\title{
An Evaluation of the Effects of the Smoking Ban at an acute NHS Trust
}

R Arack, Isle of Wight Primary Care Trust, Public Health Department, 46 Sea Street, Newport, Isle of Wight, P030 5BL United Kingdom;

H Blake, Division of Nursing, University of Nottingham Faculty of Medicine and Health Sciences, Queens Medical Centre, Nottingham, NG7 2AH, United Kingdom; S Lee, Queens Medical Campus, Nottingham University Hospitals NHS Trust, Nottingham, NG7 2UH, United Kingdom

N Coulson, Institute of Work, Health \& Organisations, University of Nottingham, International House, Jubilee Campus, Wollaton Road, Nottingham NG8 1BB.

\footnotetext{
Abstract

The purpose of this study was to explore the effects of a complete smoking ban at an NHS Trust focusing on the attitudes, compliance and smoking behaviour of NHS Staff on the smoke-free NHS policy. Questionnaires were distributed to staff 17 months after the Trust implemented its smoking ban and two months before the nationwide smoking ban. Although the study showed that a significant proportion of respondents were in favour of the ban $(78.3 \%)$, results also suggested that many staff felt that designated areas should be provided for those who smoked. Positive staff attitudes towards the ban did not seem to affect actual behaviour as staff continued to smoke on hospital grounds. This study suggests that more work is needed to enforce the smoke-free policy and increase awareness of workplace smoking cessation interventions in order to change smoking behaviour in this workplace.
} 


\section{Introduction}

The National Service Framework for Coronary Heart Disease Requirements stated that by 2001, all National Health Service (NHS) bodies, including Local Authorities, as employers would have to implement a smoking policy (DH, 2000). The Health Development Agency (2004) reported that introducing a 'smoke-free NHS' is important in sending a key health message out about creating an environment that protects the health of employers, their staff and patients. It has previously been suggested that hospitals should present this commitment to health by banning smoking from the premises altogether (Batten, 1992). In England all worksites have become smoke-free environments, although the importance of health care settings implementing such policies has long been recognised (Strobl and Latter, 1998).

An increasing number of people are now in favour of stopping smoking in public places. National statistics show that the number of people in favour of such a restriction was increased overall from $81 \%$ in 1996 to $86 \%$ in 2000, in restaurants $85 \%$ to $88 \%$, in public houses from $48 \%$ to $53 \%$ and other public places from $82 \%$ to $86 \%$ (DH National Statistics, 2007). Positive attitudes towards smoke-bans are exhibited by both smokers and non-smokers, and individuals are becoming increasingly aware of the negative connotations of smoking behaviours. For example, a survey on smoking behaviour and attitudes conducted in 2000 as part of the ONS Omnibus Survey for Department of Health showed that $71 \%$ of current smokers reported that they would like to give up smoking. Further, nine out often who wanted to give up smoking reported at least one health related problem, and $41 \%$ reported they could not afford to smoke (Smokers Related Behaviour and Attitudes, 2000). 
The 'Guidance for Smoke-Free Hospital Trusts' from the United Kingdom Health Development Agency stated a need to increase the accessibility of stop-smoking services across the UK and achieve a Smokefree NHS in order for this to be successful, training should be provided for all healthcare professionals to provide opportunistic 'stop- smoking' advice to smokers (Health Development Agency, 2005).

The 2004 White Paper 'Choosing Health: Making Healthier Choices Easier' (Dept Health, 2004) claimed that the NHS would be smokefree by the end of 2006 . At this time, extensive research of the dangers of second hand smoke were identified, as the causes of preventable diseases including lung cancer, coronary vascular disease and chronic respiratory problems (Scientific Committee on Tobacco and Health, 2004). A smoke-free environment is therefore recognised as essential in protecting the health of NHS staff and patients, given the known health risks of exposure to second hand smoke (McKee et al., 2003). Also in 2004, a survey of British Adults, conducted by MORI for Action on Smoking and Health (ASH), found that $96 \%$ of participants agreed with the NHS smokefree policy on hospitals and clinics, with $84 \%$ strongly supporting this (MORI/ASH Omnibus Poll, 2004). It has already been suggested that implementing smokefree policies in NHS hospital settings can be successful (Goseph et al., 1995 cited in Ratschen, 2008).

Nevertheless, smokers continued to be observed on UK NHS hospital sites despite clear messages about smoke-free policies. The effectiveness of smokingrelated interventions in such settings depends on the attitudes of NHS staff. The NHS as an employer has a corporate social responsibility to protect the health of its staff through the promotion of healthy behaviours and reduction of negative 
health behaviours. However, NHS employees need also to take responsibility for their own health and that of others and 'practice what they preach'. A reduction in smoking behaviours amongst health professionals is vital to ensure that they set a good example (Rosenstock et al., 1986). However, there is evidence that smoke-related attitudes differ even between healthcare professions (Dickens et al., 2004). McBride (1994) conducted a study with healthcare staff in the UK and reported that $92.1 \%$ of doctors were in support of a smoking ban for staff, compared with $62.3 \%$ of nurses. In the same study a ban for patients to stop smoking was also favoured by $98 \%$ of doctors compared with $57 \%$ of nurses. These figures are worrying given the role of nurses in promoting health to their patients. As the largest occupational group within the NHS, the Department of Health have recognised that too many of our nurses are smokers. In response to this, the NHS Smokefree Policy support from the Joint Department of Health, and the Royal College of Nursing have implemented a campaign specifically to help support nurses to quit smoking (DH Publications, Policy and Guidance, 2008). The Department of Health (DH) and the National Institute for Health and Clinical Excellence (NICE) have carried out research on workplace Health Promotion Initiatives to reduce smoking behaviour and to quit smoking long-term for employees. This guidance has been developed for NHS employees and for nonNHS professionals in local authorities, community, voluntary and private sectors (NHS, NICE Workplace health promotion: How to stop employees from stop smoking, 2007).

From the $1^{\text {st }}$ July 2007, England became smokefree in all enclosed public places and workplaces; however, employers are not legally required to help employees who do smoke to quit. It is recommended that those agencies that do provide 
support could improve people's health, reduce the risk of non-compliance with the law, and provide services for individuals to make healthier lifestyle choices. The negative health effects of smoking and the benefits of smoking bans have been acknowledged for many years, even in healthcare settings, although the implementation of such bans has taken a long time to come to fruition. Almost two decades ago, a survey conducted in Italy showed that $80 \%$ of healthcare staff favoured a total ban on smoking inside hospital buildings, although staff underestimated the effects of smoking-related health hazards (Talamini et al., 1989). At that time only $13 \%$ of nurses were aware that smoking was one of the leading preventable causes of death (Talamini et al., 1989), indicating the need for education of nursing staff about the health consequences of smoking (Boccolo et al., 1997).

More recently, Bloor et al., (2006) emphasised that staff attitudes are essential in determining the effectiveness of smoking bans. Smoking bans are known to be more effective when managers show support towards staff who smoke and wish to quit. There is also limited, evidence that smoking bans in hospital settings can encourage smokers to quit. For example, one study conducted in a large British teaching hospital on a complete smoking ban looked at nurses' smoking behaviours and their attitudes towards the current hospital policy (Strobl and Latter, 1998). Questionnaires were distributed to nurses who were smokers and ex-smokers nine months after the smoking ban was implemented. Of the smokers in this study, $21.4 \%$ stated that the ban was a reason for them to quit smoking and two out of three ex-smokers reported that the ban was the reason they had given up. However, compliance of the smoking ban was poor among patients and other staff. 
Another study in an English NHS acute and Mental Health Trust by Ratschen et al., (2008) also looked at the effects of a smokefree policy. This was a questionnaire based survey with additional semi- structured interviews, including 25 participants over the telephone and direct observation with 15 Trusts. Results from the study showed that $98 \%$ of mental health and acute settings implemented the policy, this applied to the whole premises in $84 \%$ acute and $64 \%$ mental health. However, $50 \%$ of acute and $75 \%$ mental health settings had smoking rooms or sheltered outdoor areas. The authors also identified several challenges with policy enforcement, including the risk of abuse for enforcement staff and smoking litter on the premises.

The impact of smoking bans is still under investigation in terms of their impact on smoking behaviours, particularly those of healthcare professionals. There has been research conducted on nurses' smoking behaviour and smoking behaviour by staff working on psychiatric wards. Bloor et al., (2006) assessed the effectiveness of the smoke-free ban amongst nurses at a new psychiatric hospital focussing on behaviour, attitude and compliance towards the ban. Although the ban was generally accepted by staff who worked at the hospital, it was reported that sufficient support was not given to those who wished to stop smoking. This further demonstrated the need for more specialist help for smoking cessation in the workplace as an integral part of smoking policies.

Although there is some published evidence on staff attitudes towards smokebans in the NHS, our knowledge of the impact of smoke-bans in these settings is still limited. This study therefore aims to explore the attitudes and consequent smoking behaviours of staff at a large acute NHS Trust on the smoking ban that came into effect in January 2006. The objectives of the study: 
1. To explore the attitude, behaviour and compliance of NHS employees toward the smoking ban,

2. To explore if staff have quit smoking due to the NHS ban or the national ban.

\section{Method}

This was a quantitative questionnaire survey, which included some open-ended questions. The questionnaire included items on demographics, smoking behaviour and descriptive questions on policy enforcement. A 19-item questionnaire was distributed to an opportunity sample of 350 Trust employees out of an 11,000 people workforce. Participants were recruited through hospital wards and departments who demonstrated an interest in taking part. The questions were designed to be completed by smokers, ex-smokers, non smokers and those who have never smoked. Ethical approval was granted by the ethics committee at the University of Nottingham (I-WHO) and NHS Research Governance Team at the NHS Trust. The questionnaire was confidential and did not contain any personal identifiers.

The questionnaire was administered in May 2007, 17 months after the NHS Smokefree Policy was introduced at this Trust and two months before the National Smoke Ban (1st July 2007). This was an ideal time to explore the challenges, impacts and attitudes relating to policy implementation since the ban were at its prime for controversial debate amongst employees.

\section{Pilot Study}

The questionnaire was piloted to 47 University staff based at the medical school located within the NHS Trust and the questionnaire was amended according to 
feedback. Quantitative responses were analysed using SPSS version 15.0, whilst qualitative data from the open-ended questions used thematic analysis to detect identify the main themes emerging from responses.

\section{Results}

There were 160 questionnaires completed and returned (45\% response rate). This response rate was comparable with other surveys undertaken in a hospital setting (Strobl and Latter, 1998).

\section{Quantitative Data Demographic Data}

Respondents were predominantly female (89\% females and $11 \%$ males) and between the ages of 18-65 years. The ethnic grouping of participants were predominantly Caucasian (91\%), other respondents include; Asian Indian (4.5\%), Asian Other (1.3\%), Black African (1.3\%) and other (.6\%) and those who did not wish to state $(1.3 \%)$.

Respondents came from a range of occupational groups; 38\% Nursing, 30.9\% from Administration and Clerical/Senior Managers, 17.8\% Allied Health Professionals (AHP), 2.0\% Science and Professional background, 5.3\% Technical, 3.9\% Medical and 1.3\% Auxiliary. In total, staff representation for this acute NHS Trust is approximately 11,000 in all occupation groups. Of the respondents, $48.4 \%$ never smoked, $27 \%$ ex-smokers, $19.5 \%$ were smokers and $5 \%$ occasional smokers. The number of cigarettes smoked on average was 10-15 per day with $61.5 \%$ respondents stating that they smoked regularly at work. 


\section{Current smokers' behavioural intentions}

There were $11.8 \%$ of respondents who described themselves as 'giving up smoking', $11.8 \%$ reported intending 'to give up smoking within the next month', $11.8 \%$ intend 'to give up smoking within the next six months', $17.6 \%$ reported 'to give up smoking within the next year', $11.8 \%$ intend 'to give up, but not in the next year' and finally $47.1 \%$ had no intentions of giving up smoking (Figure 1).

The results show a widespread view from respondents on their views of the smoking ban. In total $25.6 \%$ of smokers reported trying to quit since the hospital ban was implemented, whilst a further $15.4 \%$ stated that they intended to quit because of the National ban shortly to be introduced. For example respondents, both smokers and non-smokers took in to account the health effects of smoking and the health concerns on passive smoking:

Smoking and passive smoking damages health, I choose not to smoke so do not wish to smoke other people. As a healthcare organisation we must be seen promoting health and wellbeing (Ref 16).

Staff also expressed concerns about patients smoking:

Extremely annoying when I walk past patients who are in their nightwear smoking, also I have to enter the building smelling of smoke (Ref 102).

Regarding NHS budgets that are used to treat individuals who have smoke related illnesses was also reported, one respondent commented: Why should resources of health units be used to help the individual who have voluntary put themselves into a position of requiring help (Ref 146). Several staff expressed concerns over the role a hospital should play in promoting health: 
A healthier environment and makes the hospital more professional (Ref 57);

Smoking makes the area look messy; does not look good or professional and not a good advert for the NHS, supposed to promote health and wellbeing (Ref 74).

Another respondent commented;

We are a centre of excellence for lung cancer, so it does not set a very good example when staff members are seen promoting the main cause of lung cancer (Ref 153).

\section{Smoking Cessation Services}

Respondents reported that 3.4\% would find a pamphlet with useful advice beneficial, $41.4 \%$ reported free nicotine replacement therapy (gum/ patches), and 3.4\% stated that an appointment with occupational health nurse would be beneficial, 31\% wanted workplace support and $20.7 \%$ did not want any support. Ex-smokers (27\%) tended to be recent, with $91.7 \%$ who stated that they had quit less than a month ago, $1.9 \%$ one to six months ago and $6.4 \%$ reported six months to a year ago.

There was evidence to show that staff who choose to smoke should have appropriate support to stop smoking:

Provision should be made for smokers, and obviously this should not put nonsmokers at risk (Ref 79).

There was also agreement that allocated smoking areas should be provided for staff, one respondent commented:

No one enforces the ban so what is the point, it looks disgusting all the people outside in nightwear and drips. Why not give a shelter away from the entrance or better still someone to enforce the ban (Ref 46).

\section{Knowledge about Passive Smoking}


There were $91.7 \%$ respondents who stated that they believed that breathing in someone else's smoke is dangerous to health, with $1.9 \%$ reported 'no' that it was not harmful to health and $6.4 \%$ were 'not sure'.

\section{Opinions towards the smoking ban on hospital grounds}

In total 78.3\% supported the smoking ban on hospital grounds, whilst a similar amount (76.7\%) supported the National Smoking ban. However, despite this support for the ban, $63.3 \%$ felt that the hospital had not strictly enforced the ban and results showed different perceptions from a smoker's viewpoint and their right to smoke:

People smoke whether there is a ban or not, off hospital ground but the public can see it, when we had a smoke room we were out the public eye (Ref 86).

Another concern expressed was the issue of staff safety:

Smokers are subjected to increase chances of attack when forced to go off hospital grounds during night shifts. We should not be penalized for smoking and a safer alternative should be found (Ref 88).

Other information obtained through the study was the debatable issue of smokers taking longer breaks:

Smokers breaks consume far much more time from the working day (Ref 118). Another respondent stated:

I do not have any smoking breaks, why should people be allowed to do something that is bad for them, the smoke smell on staff uniforms when treating patients, looks very bad to general public when they see hospital staff smoking anywhere in the road (Ref 122).

\section{Opinions towards Hospital Smoke-ban Policy Implementation}


Overall, respondents reported that the hospital has not enforced the smoke ban, stating that staff, patients and visitors still continue to smoke on hospital premises:

Not sure of strict guidelines and I have seen people smoking outside the fracture clinic and South Block despite the ban' (Ref 08). Another respondent commented; 'Main entrance is diabolical; they said it was going to stop BUT nothing is done about it' (Ref25).

Furthermore, data collected showed strong views on the lack of patrolling that is carried out throughout hospital grounds to stop people smoking. The lack of resources given to staff to implement these policies and to make them successful. One respondent stated:

Staff members are still on the smoking wagon and I have seen attitudes displayed where staff 'don't care' and do not see the guidelines as a threat as they do not think it will happen (Ref 153).

However, a minority of staff did feel that the hospital had enforced strict guidelines, that smokers are leaving hospital premises, and there are posters around the campus, including the press media, trust briefings and signs throughout the hospital:

Good, clear signage and removal of that absolutely ridiculous smoking shelter outside (Ref 144).

Data also showed that participants were not sure how strictly the NHS Smokefree guidelines are enforced throughout the hospital because people were still seen to be smoking on hospital grounds. Other comments were made by people stating that efforts are being made to enforce the policy; however it seems that a lack of resolute action is taken against offenders. 
When participants were asked if they had any other comments, several discussed the association between the Smokefree Policy and the actual enforcement of the ban on hospital site and the health risks associated with smoking. As one respondent reported;

I feel that the Trust is not doing enough to enforce the non-smoking ban when people can freely smoke on hospital grounds unchallenged (Ref 10).

There was agreement about the smoke ban, although there was also widespread support for the idea of designated areas for those who wish to smoke.

\section{Views towards the National Smoking Ban}

Respondents demonstrated positive attitudes towards the National Smoking Ban. One respondent commented:

It will make enjoying public places more enjoyable not having to breathe in someone else's smoke (Ref 43);

I do not have to inhale other people's smoke when out, this will be better for children in public places (Ref 37).

The number of cases for passive smoking has increased over the years. A cleaner environment is a healthy environment (Ref 153).

However, results indicated provision should be in place for those who do smoke, stating that it is an individuals' choice if they wish to smoke, one respondent commented:

I agree that smokers and non-smokers should be segregated for health purposes but this can be done by allocating designated areas. This is an infringement on my human rights and I currently feel that I am considered as a second class citizen (Ref 87). 
Furthermore, there were attitudes from respondents that the government is dictating to the public:

I agree certain areas should be no smoking, but should really be allowed to smoke if you want to and not dictated too. What is the next ruling going to be?' (Ref 34).

\section{Discussion}

This study found participants to be mainly in favour of the NHS Smokefree policy. However, staff overall felt that the ban had not been enforced effectively on this site, and responses suggested that staff are often too frightened to challenge or confront individuals who do smoke on site due to the risk of abusive behaviour.

The study respondents were mostly female (89\%) and the most common occupational group for respondents were nurses (38\%). Most participants were from a Caucasian background (91\%). The study also showed that some staff did not comply with the ban and continued to smoke on hospital grounds, with others complying to the ban and a proportion encouraged to quit as a result. Our results show that compliance, behaviour and attitudes vary greatly between NHS employees. Some staff felt strongly that the smoking ban takes away freedom of choice, autonomy and is against human rights. It is thus difficult for NHS staff with these attitudes to reinforce the ban to patients who smoke whilst in hospital care. However, most participants did support the idea that premises like hospitals and other public places should have smokefree policies and designated smoking areas.

The debate surrounding smoking bans is controversial, with many staff believing that smoking is a personal choice and no support is given onsite for those who do 
smoke and wish to continue to smoke. Our findings concur with those of a similar survey carried out in 2004, which also showed that $96 \%$ of participant agreed to smokefree NHS hospitals and clinics, with 84\% strongly supporting this policy (MORI/ASH Omnibus Poll, 2004).

These results suggest that in order for smoking cessation services and support services to be accessible and beneficial, NHS Trust staff felt that free nicotine replacement therapies, and/or workplace support groups would be useful. Currently, NICE guidance to promote health and wellbeing in the workplace is being prepared; to ensure that this is beneficial, it is important that employers are aware of services and organisations in their local areas to help signpost their employees.

This study also found that the majority of staff were not familiar with Smoking Cessation Services although local services do exist and are promoted onsite. The majority of respondents reported that they would find smoking aids beneficial although these are already in place. Hocking et al., (1991) stated that the compliance of staff towards smoking bans is related to the total support offered to staff, therefore, more health promotion work at this acute NHS hospital should be undertaken to help increase awareness of smoking cessation service and to guide individuals who want to quit smoking and are looking for support. Additionally, training for staff should be available that covers regular update on the effects of smoking, health promotion initiatives and smoking cessation workshops specifically within this Trust. The majority of respondents felt that the NHS Trust had not enforced strict guidelines on the smoking ban, particularly given that people continue to smoke on hospital grounds. In order to show that contravening this Smoke-free policy is 
a serious offence for staff, patients and visitors, it is likely that the management team needs to implement the ban again to enforce smoking as a disciplinary offence and to enforce additional policing around hospital grounds. Bloor et al., (2006) showed that the attitude of staff towards workplace smoking bans has an impact on the effectiveness of such bans. Research also suggests that the attitude of staff towards the smoking ban varies with occupation, (Dickens et al., 2004). In this study the largest occupational group were nurses, and the majority of respondents did not smoke. It is therefore difficult to make conclusive statements about the attitudes of all NHS staff from these findings.

\section{Limitations:}

This study relied on self-reported questionnaires and so there is a possibility of participant bias, especially on such a controversial and sensitive topic. The response rate from returned questionnaires was approximately $45 \%$ and so we have no information about the attitudes of non-responders. Questionnaires were administered to 20 wards and departments and so the study only accessed a small sample from an employer of over 11,000 people. Further, this questionnaire comprised of only 19-items and did not include objective measures of health behaviours. Therefore we cannot conclude with certainty that the smoking ban changed health per se, or health behaviours on this site. Despite these limitations, the survey indicated a general pattern of attitudes and behaviours and provides some insight about the attitudes, opinions and compliance towards the smoking ban of these hospital employees. 


\section{Suggestions for Further Research:}

The effects of the smoking ban needs to be explored further, with a larger sample, perhaps incorporating objective measures of health and focus group interview on multiple NHS sites, to further observe the attitude, compliance and behaviour of NHS staff. Future interventions and evaluations should be conducted in partnership with Public Health services, Smoking Cessation teams and other relevant services in the area.

Studies targeting different ethnic groups may help to sustain any reduction in smoking behaviour as a result of workplace smoking bans and smoking cessation services need to offer alternative options to ensure vulnerable groups are targeted and appropriate support material is available.

Currently, there is no standardised attitude scale on smoking behaviour for use in the workplace, and further development of scales and measures on attitudes towards smoking bans would help support and evaluate workplace Smoke-free policies in the UK. There is also a need for further work promoting awareness about health promotion initiatives for smoking cessation and evaluating workplace initiatives to reduce smoking, to support those smokers who want to quit.

\section{Conclusion}

This study found that, despite perceptions of staff support for the NHS smokefree policy, the ban at this large acute NHS hospital has been relatively ineffective in its first 17 months with either discouraging staff and patients from smoking on-site or encouraging NHS staff to quit smoking altogether. Results suggest that the ban is not sufficiently enforced and that support services are either absent or not well-publicised. The focus of the smoke-free campaign resulted in smoking 
staff feeling alienated. These findings are a concern to health promoters and alternative anti-smoking messages need to be explored and enforcement methods of smoke bans effectively implemented.

\section{References}

Anderson C, Sengupta S and Coleman J (1999). Implementing smoking policies within Trusts: nurses' perceptions and views of effectiveness and implications. Journal of nursing management. 7, p. 349-354.

Batten L (1992). Air freshener. Health Service Journal. 102, p. 31.

Bloor RN, Meeson L and Crome IB (2006). The effects of a non-smoking policy on nursing staff smoking behaviour and attitudes in a psychiatric hospital. Journal of Psychiatric and Mental Health Nursing. 13, p. 188-196.

Boccoli., E. Federici, A., Trianni, G.L., and Melani, A. S. (1997) Changes of smoking habits and beliefs during nurse training: a longitudinal study. European Journal of Epidemiology. 13, p. 899-902.

Boccoli E, Federici A, Trianni GL and Melani AS (1997). Changes of smoking habits and beliefs during nurse training: a longitudinal study. European Journal of Epidemiology. 13, p. 899-902.

Department of Health (1998). Smoking Kills. The Stationary Office: London. 
Department of Health (2000). The National Service Framework for Coronary Heart Disease. Retrieved from: http://www.doh.gov.uk/nsf/coronary.htm (Accessed on 27th June 2007).

Department of Health (2007). Statistics on smoking: England 1976 to 1996.

Retrieved from: http:// www.dh.gov.uk/en/Publicationsandstatistics/ Statistics/StatisticalWorkAreas/Sta... Accessed on 27th June 2007.

Department of Health (2007). Statistical bulletin, 2003/21: Statistics on smoking: England 2003. Retrieved from:

http://www.dh.gov.uk/en/Publicationsand statistics/Statistics/StatisticalWorkAreas/Sta... (Accessed on 27th June 2007.

Department of Health (2007). Smoking related behaviour and attitudes. Retrieved from: http:// www.statistics.gov.uk/pdfdir/srba0901.pdf E (Accessed on 26th June 2007).

Dickens GL, Stubbs JH, Haw CM (2004). Smoking and mental health nurses: A survey of clinical staff in a psychiatric hospital.] Psychiatric Mental Health Nursing. 11, p. 445-51.

Fee E and Brown TM (2004). Hospital Smoking bans and their impact. American Journal of Public Health. 94, (2), p. 185. 
Health Development Agency (2004). The case for a completely smoke-free NHS in England. Retrieved at: http://www.hda.nhs.uk.

Jarvis MJ, Wardle J and Owen L (2003). Prevalence of hardcore smoking in England, and associated attitudes and beliefs: cross sectional study. British MedicalJournal, p. 1-5.

Longo DR, Fieldman MM, Kruse RL, Brownson RC, Petroski GF and Hewett JE (1998). Implementing smoking ban in American hospitals: results of a national survey. Tobacco Contrology. 7, p.47-55.

McBride A (1994). Health promotion in hospitals and practices of hospital nurses. Journal of Advanced Nursing. 20,92-100.

McKee M, Gilmore A and Novotny TE (2003). Smoke free hospitals. A $n$ achievable objective bringing benefits for patients and staff. British Medical Journal 326: 941-2.

McNeill A and Owen L (2005). NHS Health Development Agency: Guidance for smokefree hospital trusts. Retrieved from: http://www.cleanairward. org.uk/downloads/HDAGuidance.pdf Accessed on June 22, 2007) McNally et al., (2006). A survey of staff attitudes to smoking-related policy and intervention in psychiatric and general health care settings. Journal of Public Health. 28 (3), p. 192-196. 
Health Development Agency. Guidance for Smoke-free Hospital Trusts. (2005) London: HAD.

MORI/ASH Omnibus poll (2004). Smoking Public Places. Retrieved at www.mori.com/polls/2004/relocation of smoking at work. Health Promotion International. 15 (2), p. 125-133.

NHS National Institute for Health and Clinical Excellence (2006). Brief interventions and referral for smoking cessation in primary care and other settings. Public Health Intervention Guidance no 1 Retrieved from: http://www.ncsct.co.uk/usr/pub/guidance-on-brief-interventions-and-referralfor-smoking.pdf (Accessed on August, 9, 2007).

National Institute for Health and Clinical Excellence, NHS (2007). Workplace interventions to promote smoking cessation.

NHS National Institute for Health and Clinical Excellence (2007). Workplace health promotion: how to help employees to stop smoking. Public Health Intervention guidance 5. Retrieved from:

http://www.ncsct.co.uk/usr/pub/guidance-on-workplace-health-promotion.pdf

Parry 0, Platt S and Thomson C (2000). Out of sight, out of mind: workplace smoking bans and the relocation of smoking at work. Health Promotion International. 15 (2), p. 125-133. 
Scientific Committee on Tobacco and Health (2004). Secondhand smoke: review of evidence since 1998. Update of evidence on health effects of second hand smoke. London: Department of Health: Retrieved from:

www.advisorybodies.doh.gov.uk/scoth/PDFS/ scothnov2004.pdf (Accessed on August, 9, 2007)

StroblJ and Latter S (1998). Qualified nurse smokers' attitudes towards a smoking ban and its influence on their smoking behaviour. Journal of Advanced Nursing. 27, p. 179-188.

Talamini R, Bidoli E, Serraino S and Bollini P (1989). Habits and opinions about cigarette smoking among medical, nursing and technico- administrative staff at the Magenta Hospital (Local health unit no. 72). Epidemiologia and Prevenzione. $11,35-40$.

Taylor T, Lader D, Bryant A, Keyse L and Joloza M T (2005). Smoking related behaviour and attitudes, National Statistics: London: Office for National Statistics Retrieved on: http://www.statistics.gov.

uk/downloads/theme_health/Smoking2005.pdf (Accessed June 22, 2007).

Williang I, and Ladelund S (2004). Smoking behaviour among hospital staff still influences attitudes and counselling on smoking. Nicotine and Tobacco Research. 6, 369-375. 
Willemsen MC, Gorts CA, Van Soelen P,Jonkers Rand Hilberink SR (2004).

Exposure to environmental tobacco smoke (ETS) and determinants of support

for complete smoking bans in psychiatric settings. Tobacco Contrology, 13, 180185. 